\title{
"O Que Eu Faço Agora?": Reflexões sobre Imersão e Identificação na Aprendizagem com Role-Playing Game Digital
}

\author{
Fernando R. de Lima Júnior'1, Flávia M. de A. e Peres², Ladjane de F. R. Caporal ${ }^{3}$ \\ ${ }^{1}$ Departamento de Psicologia - Faculdade de Ciências Humanas de Olinda (FACHO), \\ Olinda, PE - Brasil \\ ${ }^{2}$ Departamento de Educação, Programa de Pós-graduação em Educação, Culturas e \\ Identidades - Universidade Federal Rural de Pernambuco (UFRPE), Recife, PE - Brasil \\ ${ }^{3}$ Departamento de Psicologia - Faculdade de Ciências Humanas de Olinda (FACHO), \\ Olinda, PE - Brasil \\ fernando.rlimajr@gmail.com, peres.flavia@gmail.com, \\ ladjane.caporal@gmail.com
}

\begin{abstract}
In the dialogue between historical-cultural psychology and psychoanalysis, we present a discussion on the use of digital role-playing games as an instrument for school learning based on the interactive approach that we extract from a learning experience with students in the 6th year of middle school. In this study, the result of a qualitative and participatory research, we are anchored in an educational vision that seeks to provide the student with an immersive and personal space for the appropriation of knowledge in the relational encounter with his social others from the culture. For this, we assume a reflexive and defensive position in the use of digital games as potential learning instruments, not merely didactic, in which the student can find something of himself and in this create new ways of knowing and learning.
\end{abstract}

Resumo. No diálogo entre a psicologia histórico-cultural e a psicanálise, apresentamos discussão sobre o uso do role-playing game digital como instrumento de aprendizagem escolar a partir do recorte interativo que extraímos de uma vivência de ensino-aprendizagem com estudantes do $6^{\circ}$ ano do ensino fundamental. Neste estudo, fruto de uma pesquisa qualitativa e participante, ancoramo-nos em uma visão educativa que busca possibilitar ao estudante um espaço imersivo e pessoal de apropriação de conhecimentos no encontro relacional com seus outros sociais da cultura. Para isso, assumimos posição reflexiva e defensiva no uso dos jogos digitais como instrumentos potenciais de aprendizagem, não meramente didáticos, em que o estudante possa encontrar algo de si e nisto criar novas formas de conhecer e aprender.

\section{Introdução}

Intencionamos, com este artigo, refletir o uso do role-playing game (RPG) digital como instrumento de aprendizagem escolar, a partir do qual se permite a consolidação de uma prática educativa imersiva de apropriação de conhecimentos no contexto relacional que 
perpassa a interação entre estudantes e professor. Argumentamos em prol do jogo digital que pode respaldar as vivências de tal contexto a partir do caráter fluido que envolve as narrativas desta categoria de jogos. Assim, apresentamos sua potencialidade de permitir a apropriação de conhecimentos científicos e suscitar a reflexão de temas transversais caros à função social e histórico-crítica da instituição escolar.

Implicados na área de educação, realizamos uma leitura dialógica entre a psicologia histórico-cultural e a psicanálise, perpassando as compreensões vigotskianas de aprendizagem e Zona de Desenvolvimento Proximal (ZDP), bem como às articulações psicanalíticas entre educação e a ética do sujeito do inconsciente. Assim, com um recorte interativo de uma vivência de aprendizagem, realizada com estudantes do $6^{\circ}$ ano do ensino fundamental de uma escola particular da região metropolitana do Recife, em que usamos o RPG digital como instrumento lúdico de aprendizagem, articulado à disciplina Ética e Cidadania (do currículo cursado pelos estudantes), ilustramos a potencialidade deste tipo de jogos que envolve a imersão de seus jogadores pela personificação e interpretação de um personagem no mundo digital, este que, por sua vez, oferta desafios e situações-problemas para a vivência da narrativa em sua experiência virtual.

Destacamos, ainda, que as reflexões teóricas, os dados e a análise qualitativa, doravante expostos, são oriundos da pesquisa de mestrado do autor principal deste artigo.

\section{Imersão virtual e RPG digital}

Lima (2009) levantou a discussão acerca do ciberespaço e caracteriza-o em sua dimensão pública, a partir da qual o jovem pode se sentir incluído e assim fazer "a passagem do privado ao público" [Lima 2009, p. 218], socialmente esperada pelo empuxo do desenvolvimento subjetivo da juventude que convoca o sujeito ao campo das relações com os outros sociais de sua cultura. Trata-se de uma forma pela qual o sujeito pode se sentir pertencente à rede, nela agir e assim significá-la. Na interação social do ciberespaço é possível haver identificação, ainda que imaginária [Lima 2009].

Nessa perspectiva, a discussão filosófica levantada por Lévy $(1997$; 1999) levanos à refletir sobre os campos de distinção entre real e virtual, sendo esta última dimensão usualmente referida para caracterizar aquela que estaria na ordem do irreal, e o real, por sua vez, seria entendido como aquilo que necessitaria de efetivação material, concreta, palpável. Assim, o virtual existiria sem estar presente numa unidade espacial, não coexistindo com o virtual, premissa refutada pelo filósofo, que aponta a não oposição entre essas dimensões e assumido que no real o virtual pode existir. Em tal discussão, entendemos que há, sim, uma distinção conceitual entre virtualidade e realidade que diz respeito à essa materialidade concreta e ao fato do virtual prescindir da unidade espacial, porém não são conceitos opostos e sim dialéticos entre a possível realidade - que pode vir a existir na materialidade - e a virtualidade atual - que existe no tempo presente.

Nos debates filosóficos e sociológicos que envolvem o pós-humanismo e a evolução tecnológica, Felinto (2006) apontou para o estágio de transcendência das limitações físicas e biológicas da humanidade, que expressa o "desejo de ultrapassagem dos limites ou fronteiras" [Felinto 2006, p. 106] mediante a realização do abandono da condição corporal. As experiências de imersão proporcionadas pelo mundo virtual, entre 
as quais encontramos a ofertada pelo RPG digital, vem representando um possível sucesso da realização desse desejo.

Logo, as pessoas vêm permitindo uma posição singular do virtual em suas vidas, algo ponderado por Gregório (2014) quando ressalta a potencialidade do virtual para se atualizar e tentar suprir demandas do sujeito, posto que "depende [...] do que se busca no virtual e da forma como ele é utilizado" [Gregório 2014, p. 18]. Tal ponderação endossa a argumentação de Goldenberg (2017), quando este reflete que a reflexão do virtual e da imersividade que ele permite aos sujeitos não devem ser tratadas em tons apocalípticos, como se trouxessem consigo apenas implicações negativas para a subjetividade humana. Essas implicações condicionam-se também ao modo de uso dos recursos tecnológicos contemporâneos, particularmente quando esses envolvem a intencionalidade de cargas ideológicas que determinam modelos de mundo e formas de existência significados em favor da lógica hedonista do consumismo neoliberal [Lima Júnior 2020].

A virtualidade permite uma relação especular, na qual o sujeito pode ir ao encontro de um reconhecimento subjetivo atrelado ao seu eu narcísico (Eu ideal) ou rumar para a constituição de um eu atravessado pelas condições simbólicas marcadas pela alteridade (Ideal de Eu). As personificações através de um avatar, na vivência de uma narrativa RPG, situa o sujeito frente à possibilidade de desejar o deslumbramento do Outro frente à imagem que ali projeta - ser reconhecido, valorizado -, configuração própria da condição do imaginário ensinado por Lacan (2009), sem o atravessamento mediativo do campo simbólico. Essas mesmas personificações na rede digital, quando oferta ao sujeito o encontro com a possibilidade de não apenas ser reconhecido por este Outro, mas construir meios de fazer-se reconhecer, exigindo-lhe energia psíquica para tal empreitada, situa-o num salto qualitativo que o conecta ao simbólico da cultura e a inscrição da alteridade: ou seja, não apenas repete, reproduz e se aliena ao discurso pelo qual sente-se determinado, mas apropria, cria e transforma seus objetos culturais.

Vigotski (2009) ressalta a importância da imaginação para a aprendizagem humana. No jogo e na brincadeira o sujeito pode apropriar as significações de si, do outro e do seu contexto histórico-cultural, algo que apenas se faz possível pela interação com esse outro social, que ocupa uma função mediadora para o sujeito em constituição. É a partir de tal interatividade mediadora que o sujeito pode construir sentidos próprios ao longo de sua história ontogenética de subjetivação e desenvolvimento.

Ao se representar e vivenciar as narrativas da virtualidade digital, o jogador, no RPG, expressa elementos de sua história e ali pode (re)construir outros significados e sentidos para a vida. Imaginando, interpretando e (re)criando no cenário virtual, o sujeito pode deparar-se com o inusitado e nisto se deparar com o não saber que as atividades imersivas the ofertam, para com isso, mediante o encontro com seus pares por amigos que se põem a jogar, ou pelas relações estabelecidas no âmbito virtual (até mesmo na relação virtualizada com os personagens fictícios da trama do jogo) - galgar rumo ao caráter simbólico-mediativo da alteridade [Lima Júnior, 2020].

Virtual e real não se dissociam; relacionam-se dialeticamente entre a condição de uma possível realidade e a temporalidade atual da virtualidade [Gregório 2014]. O real ancora-se em uma configuração espaço-temporal respaldado por uma lógica concreta e materializável, o virtual, por sua vez, é sustentado pela lógica abstrata, em uma temporalidade distinta, existindo "em potência e não em ato" [Gregório 2014, p. 24]. 
Na ação inventiva de uma narrativa RPG, pela personificação e interpretação do personagem no cenário virtual, o jogador:

[...] não somente interage, brinca, fantasia, mas se depara com novas relações de objeto. Relações que são encenadas a partir da vivência pelo avatar, que é tomado como sendo seu ou um representante de si. Um representante metamórfico que tem a possibilidade de não possuir as falhas narcísicas de seu usuário que o constituiu como sujeito. Portanto, hipotetizamos que na vivência [...] [desses jogos,] pelos avatares está inserido um investimento fundamentado pelas subjacentes bases narcísicas e identificatórias de seu usuário [Gregório 2014].

Os jogos digitais podem permitir ao sujeito um caminho pelo qual possa aventurar-se, arriscar-se e nisto obter prazer [Francisco 2014]. É "um lugar histórico de significação e construção de sentidos" [Lima Júnior, Peres e Caporal 2019], assumindo a forma de uma interação narrativa [Tisseron 2015] pela qual o sujeito pensa e interage afetivamente com o cenário, quer individualmente, quer em grupo, quase que no envolvimento de uma rivalidade edípica com o jogo, no qual busca "abater um inimigo poderoso para tomar seu lugar" [Tisseron 2015].

\section{Por uma aprendizagem imersiva e identificatória: a campanha do RPG}

A aprendizagem escolar tem o propósito de formar os estudantes para a vida entre seus pares no laço social [Mrech 2003]. Tal propósito apenas se faz possível quando situado em função do caráter histórico e social que constitui o sujeito no espaço educativo pelos entrelaçamentos filogenéticos, ontogenéticos e sociogenéticos do desenvolvimento [Vigotski 2007], da subjetivação e do próprio espaço social escolar.

O jogo aponta a vivência de aprendizagem respaldada pela suscitação do desejo de investigar, de conhecer e de buscar soluções para situações-problemas. Oferta, também, uma "possibilidade de exploração, invenção a partir de uma ordem que permite ao estudante projetar sua vida interior na atividade lúdica" [Lima Júnior 2020, p. 141].

A campanha no RPG diz respeito ao curso de atividades em uma missão que os jogadores precisarão realizar na narrativa do jogo [Marins 2017]. Nas campanhas, os jogadores encontrarão desafios e conquistas que exigirão deles atenção, raciocínio e fluência na linguagem comunicacional, em um espaço mediado pela simulação, interatividade e imersão que caracterizam tal vivência no âmbito digital, envolvendo uma sinestesia participativa nas decisões da narrativa [Antonio Junior 2014].

Tal sentido de campanha poderia se estender às vivências de aprendizagem escolar, ao assumirem caráter imersivo e identificatório no qual o sujeito possa colocar algo de si nessa construção. Por isso, - aproveitando a polissemia do termo - fazemos campanha para o uso do RPG digital como instrumento de aprendizagem, uma vez que identificamos nele a potencialidade de permitir vivências lúdicas do aprendizado curricular e das relações histórico-culturais que se inscrevem nesse contexto escolar, envolvendo discussões transversais de ordem social e existencial da vida:

[...] vida, morte, sexualidade, política, expressões de fé, diversidade cultural, preconceitos, violência, ética, moral e tantas outras que podem ser suscitadas pelos conteúdos históricos, filosóficos, mitológicos, linguísticos, artísticos, sociológicos, antropológicos e psicológicos [Lima Júnior 2020, p. 142] 
Temas que se presentificam nos conteúdos imersivos e interativos desta categoria de jogos digitais.

Estudos acerca do uso dos RPG no cenário educacional, também em sua imersão digital [Lima Junior 2020, Marins 2017, Correa 2017, Ferreira 2016, Antonio Junior 2014, Melo 2014], apresentaram o potencial deste instrumento ao proporcionar aprendizagem de forma ativa e significativa, ao romper com os paradigmas tradicionais de ensino e educação, que se demonstraram inócuos para a contemporaneidade. Melo (2014) ressalta que a aprendizagem através dos RPG, usados em seu caráter processual e vivencial, não meramente didático, fundamenta "o aprender a ser, a viver, a aprender e a conhecer [...] a fim de problematizar e conectar vida e contexto dos estudantes" [Melo 2014, p. 21].

Nesse princípio, o RPG deve ser vivenciado para a construção de um espaço no qual os estudantes possam partilhar saberes ao passo que, ao longo da narrativa digital, em momentos de frustração e satisfação que perpassam o percurso da aventura imersiva, também possam demandar interesse por pesquisar e por conhecer na interlocução com seus pares e com o professor. Nesse percurso, o jogo transcende sua função de instrumento e passa ser, ele próprio, aprendizado [Correa, 2017], cujas regras, vivências e construções cognoscentes serão apropriadas pelo sujeito através da vivência lúdica de aprendizagem entre seus pares e seu professor.

Nisso, percebemos a noção de ZDP postulada por Vigotski (2007) quando tal vivência permite ao professor (que, na escola, assume a função de mediador) a construção compreensiva de como o estudante está apropriando um dado conhecimento e assim o transformando em algo próprio (de si, para si e entre os outros), num espaço simbólico intersubjetivo [Lima Júnior, Peres e Caporal 2019]. Vigotski (2007) aponta a ZDP como ferramenta processual que permite a percepção do aprendizado do estudante, não apenas considerando o que já fora desenvolvido (nível real), mas, na compreensão do processo em curso, avaliar e manter o foco sobre aquilo que está em potencial, apostando naquilo que o sujeito pode alcançar (nível potencial). É justamente neste hiato espacial intersubjetivo simbólico, entre nível real e nível potencial, que se encontra a ZDP [Vigotski 2007].

A escola se ocupa da responsabilidade do ensino institucional e sistematizado do saber científico. As vivências que se consolidam neste espaço social têm repercussão sobre o próprio desenvolvimento humano, sendo fundamental o reconhecimento ético de sua função social para "o avanço da sociedade como um todo, pois é na e pela apropriação dos conteúdos aí veiculados que o homem se constitui enquanto sujeito consciente, crítico, agente da história" [Ferreira 2016, p. 35]. Nesse entendimento, essa instituição não cumpre seu papel quando sistematizada por visões autoritárias embasadas na crença de que um indivíduo detentor de um conhecimento possa transferilo a outro que se coloca numa posição passiva de escuta e repetição (bem o que o modelo técnico-capitalista e neoliberal almeja consolidar). A aprendizagem, também na configuração escolar, acontece a partir de seu caráter interativo, dinâmico e relacional através da mediação entre os sujeitos que se põem a vivenciar o conhecimento, tanto com aqueles que possuem maior experiência em relação a um conhecimento (como no caso de quem ocupa a função do professor ou dos estudantes que já estão em um nível real frente ao conhecimento), quanto com aqueles que estão na condição de paridade (estudantes que se encontram em um nível potencial no seu processo de desenvolvimento). 
Nesta visão colaborativa e coparticipativa de educação, as experiências cognoscentes e existenciais - podem ser elaboradas em seu caráter processual. Nisto, como preconiza a psicanálise, há um encontro entre a educação e a própria subjetivação do humano e a consolidação de seu modo singular de desejar [Coutinho e Carneiro 2016]. Trata-se da instauração de uma transmissão respaldada por uma "transferência de trabalho" [Mrech 2003, p. 140], pela qual o sujeito pode investir psiquicamente para se mobilizar a criar, trabalhar, ler e escrever na relação com seus outros do contexto escolar. É importante que a escola oferte ao estudante espaço e abertura para que exercitem suas relações e a construção de significações para suas próprias experiências consigo, com os outros e com o conhecimento científico, sem jamais os constranger à configuração do acúmulo exacerbado desses conhecimentos, nos moldes de uma educação bancária, como bem refletiu Paulo Freire.

A imersão escolar pode aproximar-se à imersão dos jogos digitais de forma a proporcionar prazer aos estudantes quando na cena real da escola eles podem encontrar algo de si, para si e entre outros, de forma próxima ao que costuma acontecer na cena virtual do jogo. Por isso, a campanha (novamente nos aproveitando da polissemia deste termo) do RPG digital no espaço escolar pode permitir uma aprendizagem lúdica, experienciando, em princípios sociointeracionistas e crítico-reflexivos, os conteúdos escolares, as relações e os diálogos temáticos sobre a vida no laço social, especialmente vivenciados pela aproximação da condição desejante e identificatória do estudante: que o faz criar, recriar e transformar os conteúdos que apropria.

\section{O jogo, a vivência e a interação: "o que faço agora?"}

O RPG, como processo que envolve imaginação, identificação e aprendizagem, em um contexto interativo e imersivo digital, é um instrumento de criatividade, tanto por ser uma invenção criativa, quanto por sua vivência necessitar de criatividade para a superação dos desafios da narrativa e da campanha do jogo virtual. Nessa condição, tem a potencialidade de ser vivenciado como um instrumento educativo, envolto pelo espaço potencial de aprendizagem que pode ofertar aos estudantes nele se inserirem ludicamente e com prazer.

Realizamos sessões de imersão no universo do Ragnarök ${ }^{\circledR}$ Online RPG com 8 estudantes do $6^{\circ}$ ano do ensino fundamental de uma escola privada de um município da região metropolitana do Recife-PE. Esta vivência foi articulada à disciplina Ética e Cidadania, que integra o currículo escolar cursado pelos estudantes participantes, justamente com o objetivo de percebermos como o RPG digital pode ser vivenciado como instrumento de aprendizagem. Dessa forma, neste artigo, apresentamos um recorte interativo vivenciado nestas sessões que nos permite ilustrar a potencialidade desta estratégia lúdica, bem como apontar processos de apropriação e identificação que podem se presentificar ao longo da investigação qualitativa e participante realizada como pesquisa de mestrado do autor principal deste artigo.

$\mathrm{O}$ recorte que apresentamos traz à cena 4 estudantes que interagem ao longo de uma das sessões de imersão. Nesta sessão, a primeira de contato e imersão direta com o jogo digital (pois nas sessões anteriores realizamos explicações introdutórias sobre a pesquisa e os processos de inscrição dos estudantes na plataforma do jogo), uma questão circulou de forma bem intensa e marcante entre os participantes, neste momento de encontro com o jogo e com o outro colega na interface virtual: “o que faço agora?". Por vezes, convocavam o mediador da vivência (o pesquisador principal do estudo) para dar-lhes esta resposta, mas que, sempre que a questão (repetidas vezes) era levantada, em tempo quase que imediato, outro estudante participante, que tinha, ou supunha ter, mais experiência no jogo, respondia 
ao colega que demandava a resposta. A interatividade, na cena digital (dos estudantes que se encontravam na virtualidade do jogo para jogar) e na cena real (dos estudantes que dialogavam presencialmente e se relacionavam com os meios tecnológico-digitais para poder cursar a experiência do jogo), envolvia os estudantes de forma que buscavam o encontro do outro na narrativa digital que se iniciara, perguntavam se um via o outro e buscavam, conjuntamente, responder sobre o que precisariam fazer para resolver os impasses que eram propostos pela imersão no RPG.

Abaixo, expomos o recorte da videografia da sessão em foco (Figura 1), seguido da transcrição da cena que analisamos neste trabalho:

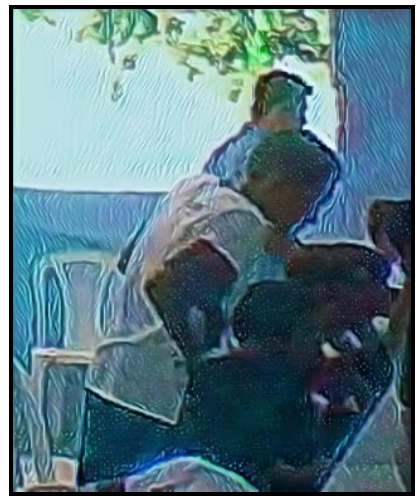

Figura 1. Registro visual da interação - 3a Sessão

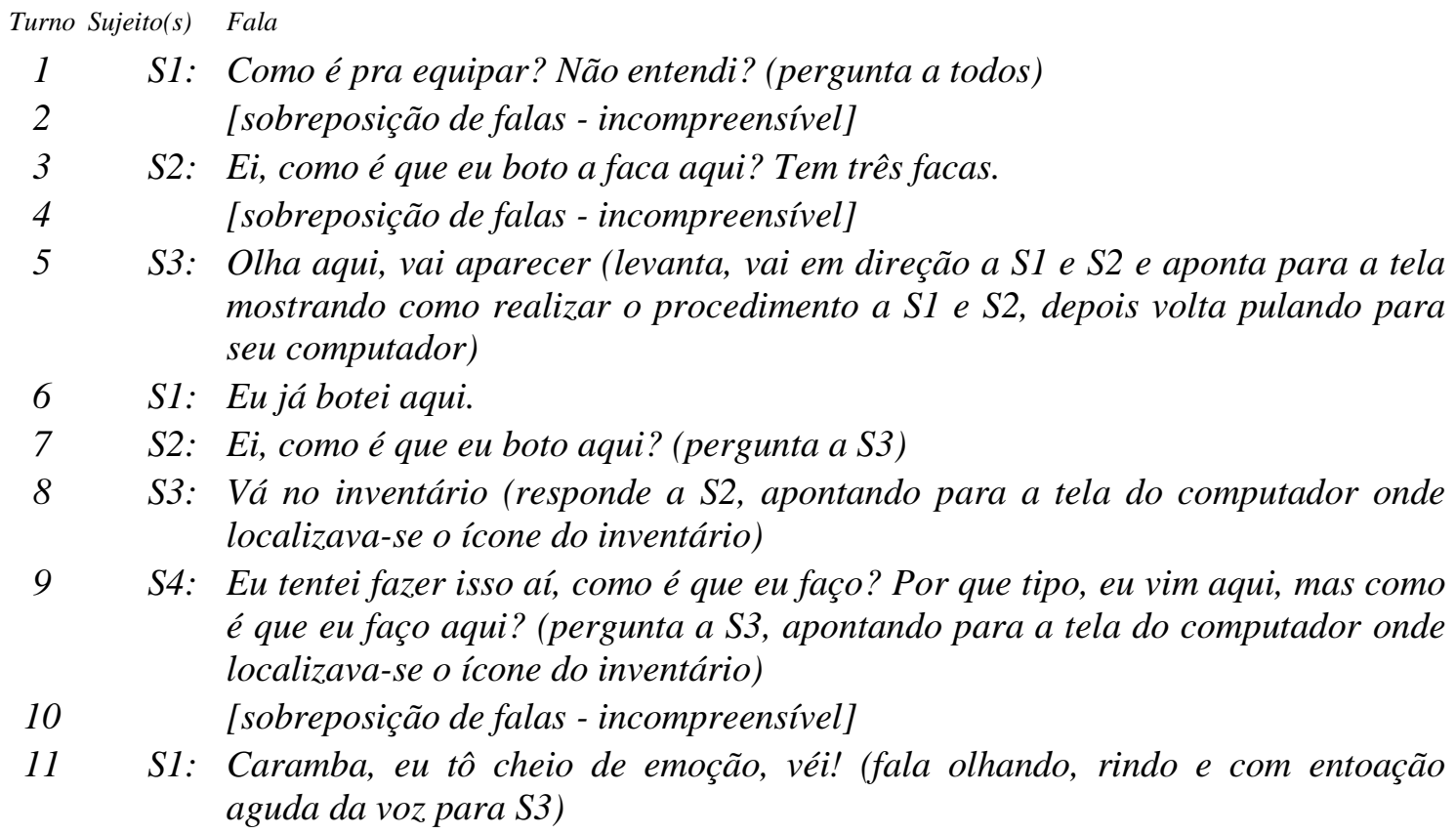

Destacamos o caráter interativo e mediativo que envolve a aprendizagem que esta cena pode ilustrar. Por ele, também destacamos a relação entre pares para o processo de apropriação de conhecimentos, algo imbuído de fatores que consolidam o próprio caráter mediativo que se materializa na interação entre os estudantes participantes. Observamos a função de mediação que S3 (vide turnos 5 e 8 ) ocupa frente à apropriação de um determinado conhecimento que S1, S2 e S4 demandam (vide turnos 1, 3, 6, 7 e 9) a fim de continuarem o percurso no jogo. S3 (vide turnos 5 e 8), mediante fala e gestos, apresenta uma resposta aos questionamentos de seus colegas, nisto, com sua mediação, também registramos a sua ação sobre o campo de aprendizagem em que se constitui a ZDP. S3, tendo já apropriado o conhecimento que seus colegas precisariam adquirir, e assim estando 
em um nível real de conhecimento, age sobre o nível potencial de conhecimento de seus colegas a fim de que eles, pela interação - através de sua fala e de seus gestos -, possam chegar ao mesmo nível de conhecimento real que se encontra. Algo que perpassa a própria construção de sentidos que se configura o processo de aprendizagem na teoria vigotskiana.

$\mathrm{Na}$ disciplina de Ética e Cidadania, os estudantes vinham discutindo sobre a compreensão histórica e filosófica, também conceitual, do significado de colaboração. Para isso, o professor da disciplina relatou que leu e discutiu textos com os estudantes, bem como assistiram e debateram sobre filmes que suscitaram o diálogo sobre a temática. Pela vivência do RPG digital, a discussão acerca do conceito de colaboração transpassou o ler, o assistir e o discutir e assumiu a ordem do experienciar, do vivenciar e do se envolver, haja vista que os estudantes, ao longo da vivência, precisaram fazer uso da colaboração entre os pares para poderem superar os desafios do jogo. A princípio, pode-se pensar que a vivência não oferta a apropriação conceitual do conteúdo, mas aqui registramos e defendemos uma outra posição de educação: uma em que o estudante se encontre socialmente com seus pares e nisto possa aprender criticamente, também as definições conceituais, justamente atrelando e experienciando as articulações que circunscrevem o pensar teórico e o seu próprio envolvimento na ordem prática e expressiva de sua realidade. O RPG digital pode ofertar isto, e ilustramos pela ação colaborativa acima transcrita, quando S3 se envolve com seus pares para lhes transmitir uma forma de superar a dificuldade e de encontrar uma resposta para "o que fazer agora?".

A vivência do RPG digital, como anteriormente discutimos, suscita nos jogadores o interesse por conhecer o desconhecido (dos desafios e dos diversos rumos que a narrativa digital pode apontar) a partir dos trajetos singulares que o jogo, criativamente, oferece, ao passo que exige dos jogadores a criatividade e o esforço psíquico para cursar tal trajeto, algo que afeta à cognição, à aprendizagem, perpassando as funções psicológicas superiores e o investimento do desejo de conhecer do sujeito para resolver os problemas e com isto aprender. Ao longo de praticamente toda a sessão, na imersão no jogo, os participantes deparavam-se com situações-problema que lhes colocava frente ao não saber o que fazer, como, em alguns momentos, em tom de brincadeira, um dos participantes falava em tom melódico, cantarolando: "eu não sei o que fazer".

O jogo proporcionou aos estudantes um encontro com esse "não saber" e a frustração que ele desencadeia, consideravelmente sentida nos momentos em que o jogo confrontava-lhes com a dificuldade da própria jogabilidade, como: que controles usar ou que procedimentos realizar para a aquisição ou uso de determinados objetos necessários para a continuidade da narrativa; qual o próximo passo a ser dado ou que caminho deveria ser seguido a partir das instruções que recebiam dos personagens do próprio mundo virtual. A interlocução acima transcrita enuncia um destes momentos de frustração que atravessa, também, a própria condição do aprendizado quando estudantes, frente a um conhecimento, possivelmente, novo para eles, não sabem de fato "o que fazer" e necessitam da mediação de um outro para assim descobrir os significados que circundam este "novo" conhecimento e atribuir-lhe sentido para que de fato lhes faça sentido. Atividade que não necessita ser ocupada apenas pelo professor, mas que precisa ser realizada por um sujeito que tem maior experiência em relação ao objeto de conhecimento - neste caso transcrito se tratou de como equipar a personagem com os itens à disposição no jogo -, que também pode ser o semelhante, o colega, o par.

É importante observarmos que nos momentos em que essas interrupções das ações com a interface do jogo digital aconteciam, havia uma quebra no processo imersivo propriamente dito, que levava os sujeitos a falarem e recorrerem ao outro social não para vivenciar o jogo propriamente dito, mas para tratar de aspectos da interface ou da 
jogabilidade, trazendo os estudantes do contexto virtual imersivo para um plano presencial, corporificado, em direção oposta, embora relacionada, à imersão no virtual. Essas trocas discursivas acerca da interface ou do que fazer em relação ao jogo digital, também contribuem para aprendizados de uma ordem procedural que favorecem a imersão na cultura digital como um todo.

A interação com seus pares, em posição responsiva e colaborativa, sem hierarquias, mas horizontalmente em postura colaborativa, favorece aspectos do ser com o outro e do ser consigo, fundamentais no desenvolvimento ético dos sujeitos. A disposição de elementos nas interfaces dos jogos digitais, principalmente quando projetadas com fins de atividades em contextos escolares, pode favorecer ainda mais os alcances imersivos e, logo, favorecer a aprendizagem de conceitos, ao se tornarem mais evidentes aos usuários, ocasionando menos interrupções nas ações imersivas no jogo e potencializando interações ricas de significados e sentidos.

Isso também implica a compreensão de que na aprendizagem há uma relação que não pode ser mensurada em termos de acumulação de conhecimentos, pois se refere à condição de um sujeito do inconsciente que também perpassa o envolvimento dos sujeitos que se encontram neste campo escolar. Diante desse sujeito, fundamentado pela psicanálise, a identificação encontra espaço frente à condição de transmissão de um saber, que por sua vez não se restringe a um dado conhecimento ou conteúdo a ser apropriado, mas se amplia rumo às experiências subjetivas que dizem respeito à própria subjetivação. Saber do qual o sujeito, também pela transferência que ocupa as relações humanas nesse contexto, pode encontrar-se com um outro de forma a também encontrar um lugar para si. Algo que, sob os pressupostos da ética do sujeito do inconsciente, apenas se faz possível quando o sujeito pode exercer, na educação, uma atividade criadora, em que pode produzir e colocar algo de si ao longo do processo de aprendizagem.

Tal produção, criativa, diga-se de passagem, pode ser percebida na relação de paridade entre os estudantes. Nessa interação, vimos S3 (par de S1, S2 e S4) em uma condição de transmitir um dado saber a seus pares (vide turnos 5 e 8), ocupando-se de apresentar uma resposta a um questionamento-problema que foi enunciado e estava impedindo seus colegas de darem continuidade ao curso do jogo. Analisando os elementos comunicativos que constituem esta interação, notamos que S3 recorre a gestos e à fala (vide turno 5) para apresentar instruções aos seus colegas em como deveriam proceder: ele levanta, vai em direção aos seus colegas, aponta para a tela, fala, mostra a seus colegas como realizar o procedimento que questionam e depois volta a seu lugar. Tal movimentação comunicativa poderia assemelha-se ao ir ao encontro do outro e ao encontrar, neste encontro, um lugar particular, pois S3 sai de seu lugar e vai até seus pares, transmite e produz algo de si, implica-se em dar uma instrução que diz de um saber que supõe ser seu e, posteriormente, retorna ao seu lugar pulando, demonstrando-se satisfeito. Nisso encontra um lugar particular, que tanto é o seu espaço de origem, quanto é o seu espaço subjetivo construído frente ao laço que estabeleceu em interlocução com seus colegas.

\section{Considerações finais: um saber em comum}

Ao "o que faço agora?" surge uma hipótese de resposta que pode ir ao encontro da questão fundante da aprendizagem que aqui colocamos em pauta: como vivenciar um processo educativo de forma a implicar o estudante em seu desejo, permitindo que encontre um espaço imersivo e pessoal de apropriação de conhecimentos no encontro relacional com seus outros sociais da cultura? 
O RPG digital surge como possibilidade de instrumentalização e de vivência de construção deste espaço imersivo que oscila entre as condições espaciais e temporais da realidade e da virtualidade na dinâmica digital. Esta modalidade de jogo, como ilustramos pela vivência transcrita, permite a construção de um caminho de aventuras, riscos, prazeres e frustrações, ao longo da cursividade digital, ao passo que fomenta uma atividade histórico-crítica de apropriação de significados e constituição de sentidos particulares à realidade da aprendizagem escolar: encontrando algo de si, para si e entre outros, colaborativamente, em busca de um saber em comum, partilhado e vivenciado para a resposta da questão "o que faço agora?" - nisto, a escola cumpre sua função social.

\section{Referências}

Antonio Júnior, W. (2014). "Jogos digitais e a mediação do conhecimento na perspectiva da psicologia histórico-cultural”. Dissertação - USP, São Paulo.

Corrêa, A. L. C. (2017). "Rolando dados, criando histórias, aprendendo História". Dissertação - UFRGS, Porto Alegre.

Coutinho, L. G. and Carneiro, C. (2016). "Infância, adolescência e mal-estar na escolarização", In: Psicologia Clínica, Rio de Janeiro, v. 28, n. 2, p. 109-130.

Felinto, E. (2006). “O pós-humano incipiente”, In: INTERCOM, São Paulo, v. 29, n. 2, p. $103-$ 118.

Ferreira, M. V. M. de A. (2016). "O RPG e a leitura". Dissertação - UFCG, Cajazeiras.

Francisco, S. P. (2014). “Cibercultura, jogos e aprendizado textual”. Tese - PUC, São Paulo.

Goldenberg, R. (2017). "Reflexões de um Geek", In: Baptista, A. and Jerusalinsky, J. (2017). "Intoxicações eletrônicas". Salvador: Ágalma.

Gregório, G. de S. (2014). "Do avatar ao sujeito". - Dissertação - UnB, Brasília.

Lacan, J. (2009). "Seminário I". Rio de Janeiro: Zahar.

Lévy, P. (1997). “O que é virtual?”. São Paulo: Editora 34.

Lévy, P. (1999). “Cibercultura”. São Paulo: Editora 34.

Lima Júnior, F. R. de. (2020). "Adolescência contemporânea e Ensino- aprendizagem através de Role-playing game digital”. Dissertação - UFRPE/FUNDAJ, Recife.

Lima Júnior, F. R. de. and Peres, F. M. de A. e. and Caporal, L. F. R. (2019). "Role-Playing Games Digitais e Ensino-Aprendizagem com Adolescentes em Contexto Escolar", In: Anais do IV Congresso sobre Tecnologias na Educação, Porto Alegre: Sociedade Brasileira de Computação.

Lima, N. L. de. (2009). “A escrita virtual na adolescência”. Tese - UFMG, Belo Horizonte.

Marins, E. S. (2017). "O uso de Role-Playing Games (RPG) no ensino de Ciências". Dissertação - USP, Lorena.

Mrech, L. M. (2003). "Psicanálise e Educação”. São Paulo: Pioneira Thomson Learning.

Tisseron, S. (2015). "Sonhar, fantasiar, virtualizar”. São Paulo: Edições Loyola.

Vigotski, L. S. (2007). “A formação social da mente”. São Paulo: Martins Fontes.

Vigotski, L. S. (2009). "Imaginação e criação na infância”. São Paulo: Editora Ática.

Vigotski, L. S. (2010). “A construção do pensamento e da linguagem”. São Paulo: Martins Fontes. 